www.jmscr.igmpublication.org

Impact Factor 5.84

Index Copernicus Value: 83.27

ISSN (e)-2347-176x ISSN (p) 2455-0450

crossref DOI: _https://dx.doi.org/10.18535/jmscr/v5i3.93

Journal Of Medical Science And Clinical Research

\title{
Study of Autonomic Dysfunction in Alcoholic Cirrhosis of Liver
}

\author{
Authors \\ Bhaurao D.Nakhale ${ }^{1}$, Jitendra P.Bhagat ${ }^{2}$, Monali D.Nistane ${ }^{3}$, Amol H. Dube ${ }^{4}$ \\ ${ }^{1,4}$ Government Medical College, Chandrapur, India \\ ${ }^{2,3}$ Indira Gandhi Government Medical College, Nagpur, Maharashtra, India \\ Corresponding Author \\ Dr Jitendra P.Bhagat \\ Assistant Professor, Department of Medicine \\ Address-38, Chandanshesh Nagar, Hudkeshwar Road, Nagpur-440034 \\ Email:drbhagat.jeeten@gmail.com, Mobile no. 9822641280
}

\begin{abstract}
Autonomic dysfunction is an dysfunction of the normal functioning of the autonomic nervous system that adversely affect health. Few studies suggest that autonomic dysfunction is common in liver cirrhosis, both in alcoholics and non alcoholics. Autonomic neuropathy in liver cirrhosis is characterized by predominant vagal impairment. Autonomic dysfunction accounts for a significant proportion of symptoms, which can be common, non specific and challenging to treat. Autonomic dysfunction contribute to the impaired quality of life in chronic liver disease. Hence the present study is undertaken to estimate the presence of autonomic dysfunction in patients of alcoholic cirrhosis and to determine the association between severity of of liver damage and extent of autonomic function impairment.

This hospital based cross sectional study includes 60 cases of alcoholic cirrhosis. Various tests for the cardiovascular autonomic dysfunction were done on all cases. Severity of liver damage was determined by Child-pugh class of liver cirrhosis. The data was collected and analysed at the end of study.

Autonomic dysfunction was seen in 55(94\%) cases of alcoholic cirrhotics. Only parasympathetic dysfunction was observed in 44(73.3\%) cases while only sympathetic dysfunction was seen in 2(3.3\%) cases. Combined, i.e.both sympathetic and parasympathetic dysfunction was seen in 9(15\%) cases. According to Ewings criteria, maximum cases (31) had early autonomic dysfunction while only 3(5\%) cases had severe autonomic dysfunction. There were 30(50\%) cases of Childs class B followed by 20(33\%)in Childs class $C$. Only 10(11.7\%) were included in Childs class A. There was no statistical significant association between Child-Pugh class of liver cirrhosis and autonomic dysfunction. But there was statistical significant association $(P<0.05)$ between severity of autonomic dysfunction and higher Child Pugh class of liver cirrhosis.

Autonomic dysfunction is common in alcoholic cirrhosis of liver. The severity of autonomic dysfunction increases with increase in the extent of the liver damage.

Keywords-Autonomic dysfunction, Cirrhosis of liver.
\end{abstract}

\section{Introduction}

Cirrhosis of liver is a global health problem and leading cause of morbidity and mortality. Alcohol, specifically ethanol is a potent CNS depressant with a range of effects on all systems particularly autonomic nervous system (ANS). It has been 
observed that alcoholics with liver damage have higher frequency of neuropathy than those without it. There are reports of association of chronic liver disease with autonomic neuropathy. ${ }^{2}$

Autonomic dysfunction can be primary or secondary, acute or chronic, and transient or progressive. Autonomic dysfunction is common in liver cirrhosis, both in alcoholic and non

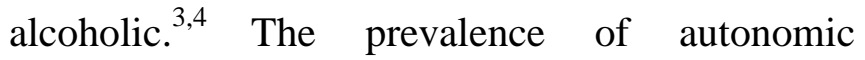
dysfunction in chronic liver disease is as high as $67 \%$ in some populations. ${ }^{4}$ One of the major contributors to a poor quality of life in chronic liver disease is autonomic dysfunction. ${ }^{5}$ It was hypothesized that patients with autonomic neuropathy are more likely to develop hepatic encephalopathy due to decreased intestinal transit time. ${ }^{6}$ Autonomic dysfunction is in independent risk factor for mortality in both compensated and decompensated cirrhotic patients. So consideration should be given to early liver transplantation in those cirrhotic patients with autonomic dysfunction. ${ }^{3,4}$ Thus, clinicians who care for patients with chronic liver disease have to recognise when autonomic dysfunction may be present, and which investigations and treatment may be of benefit.

The sympathetic (SNS) and parasympathetic nervous systems (PNS) form the two arms of the ANS through which viscera, smooth muscle and secretory glands are controlled involuntarily. The physiological responses of sympathetic nervous stimulation on cardiovascular system are increased heart rate (HR) and blood pressure (BP). The neurotransmitter of the parasympathetic nervous system is acetylcholine. The stimulation of the parasympathetic nervous system causes the cardiovascular clinical responses like decreased HR and contractility.

The pathogenesis of autonomic neuropathy in cirrhosis of liver is not fully understood. Several mechanisms have been suggested like circulatory changes in cirrhosis, metabolic and neurohormonal alteration. An increase in circulating vasodilators due to increased concentration of nitric oxide, a diseased liver and a portosystemic circulation bypassing hepatic metabolism will contribute to increased systemic vasodilatation. Circulating vasodilators will activate the reninangiotensin-aldosterone system (RAAS) and increase plasma levels of the vasoconstrictor angiotensin II. Angiotensin II may interact with the parasympathetic control of heart rate variability (HRV). Infusion of angiotensin II causes a decrease in HRV and a reduction in vagal discharges to the heart. ${ }^{7}$

There is an increased sympatomatic burden due to autonomic dysfunction in chronic liver disease, but may be overlooked in favor of laboratory markers of disease severity. Many of the symptoms of autonomic dysfunction, such as fatigue and sexual dysfunction, pose difficulties for clinicians, as they may be considered low priority, ubiquitous and unmodifiable. As autonomic dysfunction is an independent risk factor for mortality in cirrhotic patients, recognizing it will help to identify those patients who are at increased risk of death. Hence this study is carried out to determine the magnitude of autonomic dysfunction in alcoholic cirrhosis of liver and to determine its association with extent of liver damage.

\section{Materials and Methods}

The study was carried out on 60 patients of alcoholic cirrhosis of liver in the tertiary care institute. The study was approved by institutional ethics committee. This study was conducted between December 2013 to September 2015.The diagnosis of cirrhosis was based on history, clinical features and ultrasonography. Male patients consuming at least 80 grams of alcohol/day for at least 8-10 years and female patients consuming at least 20-40 grams of alcohol/day for at least 8-10 years were included in the study. Patients who were on drugs known to cause autonomic disturbances, those with history of Diabetes mellitus, leprosy, human immunodeficiency virus infection, autoimmune disorders like Systemic lupus erythematosus (SLE), Rheumatoid arthritis (RA), Sjogren syndrome etc., any 
malignancy, chronic kidney disease, patients of hepatic encephalopathy or any other acute concurrent illnesses, patients with other causes of cirrhosis like viral hepatitis, biliary cirrhosis, cardiac cirrhosis etc., patients less than 20 years of age were excluded from the study.

All patients who fulfilled inclusion and exclusion criterias were informed about the procedure of the study and were serially recruited in the study after written valid informed consent. A detailed clinical history with special reference to symptoms of autonomic disturbances, history of amount, frequency and type of alcohol consumed from each subject, general physical and systemic examination including neurological assessment and treatment received were noted. All the patients were subjected to a battery of five standard cardiovascular autonomic function tests to determine autonomic dysfunction.

\section{Tests Reflecting Cardiac Parasympathetic Damage}

\section{Heart rate response to Valsalva manoeuvre.}

The valsalva manoeuvre was performed using mercury sphygmomanometer with blowing in rubber tube and holding a pressure of $40 \mathrm{~mm} \mathrm{hg}$ for 15 seconds, with continuous ECG recording from 1 minute before the strain upto 30 seconds after the strain. The result expressed as :

Valsalva ratio $=$ Longest $\mathrm{R}-\mathrm{R}$ interval after the strain Shortest R-R interval during the strain

The result was assessed using Ewing's criteria.

\section{Deep breathing test}

The subject was asked to breathe deeply at six breaths per minute (five seconds "in" and five seconds "out") for one minute. An ECG was recorded throughout the period of deep breathing and onset of each inspiration and expiration was marked on ECG paper. The maximum and minimum R-R intervals during each breathing cycle were measured with a ruler and converted to beats/min.

The result is expressed as mean of the difference between the highest and the lowest heart rate for the six measured cycles in beats/min.

\section{Heart rate response to standing (30:15 test)}

The test was performed with the subject lying quietly on bed while the heart rate was recorded continuosly on an electrocardiograph. The subject was then asked to stand unaided and the point at starting to stand was marked on ECG paper. The shortest R-R interval at or around the $15^{\text {th }}$ beat and the longest $\mathrm{R}-\mathrm{R}$ interval at or around the $30^{\text {th }}$ beat after starting to stand were measured with a ruler. The characteristic heart rate response was expressed by $30: 15$ ratio .

\section{Tests Reflecting Cardiac Sympathetic Damage}

\section{Blood pressure response to standing}

In this test, the subject's blood pressure was measured before starting the test, while he was lying quietly and after 2-3 minutes of standing. The postural fall in Blood Pressure (orthostatic hypotension) was taken as the difference between the systolic pressure lying and the systolic Blood Pressure standing.

The results were assessed using Ewing's criteria. The fall in systolic blood pressure after standing less than $10 \mathrm{~mm}$ of $\mathrm{Hg}$ is normal, $10-20 \mathrm{~mm}$ of $\mathrm{Hg}$ is borderline and $>20 \mathrm{~mm}$ of $\mathrm{Hg}$ is abnormal.

\section{Hand grip test}

The subjects were explained about the procedure through self demonstration. The subjects were asked to hold the handgrip dynamometer in the dominant hand and compress it with maximum effort. The tension developed was measured. The procedure was repeated 3 times and the average was taken which was the maximum isometric tension ( $\mathrm{T}$ max). Then the subject was asked to maintain $30 \%$ of the $\mathrm{T}$ max for 3-5 minutes or till the subject could sustain the effort comfortably. Systolic and diastolic BP was recorded on the non-exercising arm 30 seconds before release of handgrip. The response was considered as the difference between maximum diastolic BP during exercise and the pre-exercise reading. The results were assessed using Ewing's criteria. ${ }^{8}$ 
Table 1: Ewing's criteria for Cardiovascular Autonomic Neuropathy (CAD)

\begin{tabular}{|l|c|c|c|}
\hline Test & Normal & Borderline & Abnormal \\
\hline Deep breathing test ( max-min heart rate beats/min) & $>15$ & $11-14$ & $<10$ \\
\hline Valsalva ratio & $>1.21$ & $1.11-1.20$ & $<1.10$ \\
\hline The standing 30:50 ratio & $>! .04$ & $1.01-1.03$ & $<1.00$ \\
\hline $\begin{array}{l}\text { Blood pressure response to standing : fall in systolic blood } \\
\text { pressure in mm of Hg }\end{array}$ & $<10$ & $10-20$ & $>20$ \\
\hline $\begin{array}{l}\text { Blood pressure response to sustained handgrip : rise in diastolic } \\
\text { blood pressure in mm of Hg }\end{array}$ & $>16$ & $11-15$ & $<10$ \\
\hline
\end{tabular}

Normal $=$ all test normal or 1 test borderline.

Early $\mathrm{CAD}=$ one of the three heart rate test abnormal or 2 borderline.

Definite $\mathrm{CAD}=2$ heart rate tests abnormal .

Severe CAD $=2$ heart rate tests abnormal +1 or both blood pressure tests abnormal.

A simple set of clinical and laboratory features as devised by Child and Turcotte (later modified by Pugh and named Child- Pugh criteria) were used in the study to quantify the severity of liver damage in patients.

Scoring is done on the basis of degree of ascites, encephalopathy, hypoalbuminaemia, and hyperbilirubinaemia, hypoprothrombinaemia. The score of each is added to classify a patient of the parameters in an individual as belonging to Child class A, B, or C (table 2). This grading of cirrhosis was originally devised to help select patients with cirrhosis for portal systemic shunt surgery and it has been shown to have prognostic value in several studies.

Table 2: Modified Child-Pugh Classification: ${ }^{9,10}$

\begin{tabular}{|c|c|c|c|c|}
\hline Factor & Units & 1 & 2 & 3 \\
\hline Serum Bilirubin & $\begin{array}{c}\mathrm{mmol} / \mathrm{L} \\
\mathrm{mg} / \mathrm{dl}\end{array}$ & $\begin{array}{l}<34 \\
<2.0\end{array}$ & $\begin{array}{c}34-51 \\
2.0-3.0\end{array}$ & $\begin{array}{l}>51 \\
>3.0\end{array}$ \\
\hline Serum Albumin & $\begin{array}{l}\mathrm{g} / \mathrm{L} \\
\mathrm{g} / \mathrm{dl}\end{array}$ & $\begin{array}{l}>35 \\
>3.5\end{array}$ & $\begin{array}{c}30-35 \\
3.0-3.5\end{array}$ & $\begin{array}{l}<30 \\
<3.0\end{array}$ \\
\hline Prothrombin Time & $\begin{array}{c}\text { Seconds } \\
\text { prolonged } \\
\text { INR }\end{array}$ & $\begin{array}{l}0-4 \\
<1.7 \\
\end{array}$ & $\begin{array}{c}4-6 \\
1.7-2.3 \\
\end{array}$ & $\begin{array}{r}>6 \\
>2.3 \\
\end{array}$ \\
\hline Ascites & & & Easily controlled & Poorly controlled \\
\hline Hepatic Encephalopathy & & & minimal & Advanced \\
\hline
\end{tabular}

Child-Pugh class A: score 5-6

Child-Pugh class B: score 7-9

Child-Pugh class C: score 10-15

\section{Results}

Total sample size in the study was 60 cases of alcoholic cirrhosis of liver

Table 3:Age wise distribution of cases of alcoholic cirrhosis of liver

\begin{tabular}{|l|c|c|}
\hline Age in years & Number $(\mathrm{n}=60)$ & Percentage \\
\hline $21-30$ & 3 & 5 \\
\hline $31-40$ & 18 & 30 \\
\hline $41-50$ & 27 & 45 \\
\hline $51-60$ & 12 & 20 \\
\hline Total & 60 & 100 \\
\hline
\end{tabular}

Maximum number of patients were in 41-50 years of age group.
Only $1(1.7 \%)$ out of 60 cases of alcoholic cirrhosis of liver was female. Rest 59 (98.3\%) cases were male.

55 out of 60 cases were found to have cardiovascular autonomic dysfunction.

Table 4: Distribution of patients with cardiovascular autonomic dysfunction (CAD)

\begin{tabular}{|l|c|c|}
\hline $\begin{array}{l}\text { Cardiovascular autonomic } \\
\text { dysfunction(CAD) }\end{array}$ & $\begin{array}{l}\text { Number } \\
(\mathrm{n}==60)\end{array}$ & Percentage \\
\hline Normal & 5 & 8.3 \\
\hline Only sympathetic dysfunction & 2 & 3.3 \\
\hline Only parasympathetic dysfunction & 44 & 73.3 \\
\hline $\begin{array}{l}\text { Combined(both sympathetic and } \\
\text { parasympathetic dysfunction) }\end{array}$ & 9 & 15 \\
\hline
\end{tabular}


Majority $(73.3 \%)$ of the patients had only parasympathetic dysfunction while few cases (3.3\%) had only sympathetic dysfunction. Combined, i.e.both sympathetic and parasympathetic dysfunction was seen in $15 \%$ cases.5 $(8.3 \%)$ cases didn't have any cardiovascular autonomic dysfunction. Considering either sympathetic or parasympathetic dysfunction, 11 $(18.3 \%)$ out of 60 cases had sympathetic and $53(88.3 \%)$ out of 60 cases had parasympathetic dysfunction.

Table 5: Distribution of cases according to severity of cardiovascular autonomic dysfunction (CAD) as defined by Ewing's criteria

\begin{tabular}{|l|c|c|}
\hline Severity of CAD & Number $(\mathrm{n}==60)$ & Percentage \\
\hline Normal & 5 & 8.3 \\
\hline Early CAD & 31 & 51.7 \\
\hline Definite CAD & 21 & 35 \\
\hline Severe CAD & 3 & 5 \\
\hline
\end{tabular}

Majority (51.7\%) of the patients had early cardiovascular autonomic dysfunction (CAD).

Table 6: Association of cardiovascular autonomic dysfunction(CAD) and Child -Pugh class of liver cirrhosis

\begin{tabular}{|l|c|c|c|}
\hline \multirow{2}{*}{$\begin{array}{l}\text { Child Pugh } \\
\text { classification }\end{array}$} & \multicolumn{3}{|c|}{$\begin{array}{c}\text { Cardiovascular autonomic } \\
\text { dysfunction(CAD) }\end{array}$} \\
\cline { 2 - 3 } & $\begin{array}{c}\text { Present } \\
\mathrm{n}=55\end{array}$ & $\begin{array}{c}\text { Absent } \\
\mathrm{n}-5\end{array}$ & P value \\
\hline $\begin{array}{l}\mathrm{A} \\
\mathrm{n}=10\end{array}$ & 9 out of 10 & 1 out of 10 & \\
\hline $\begin{array}{l}\mathrm{B} \\
\mathrm{n}=30\end{array}$ & $\begin{array}{c}27 \text { out of } \\
30\end{array}$ & 3 out of 30 & \\
\hline $\begin{array}{l}\mathrm{N} \\
\mathrm{n}=20\end{array}$ & $\begin{array}{c}19 \text { out of } \\
20\end{array}$ & 1 out of 20 & \multirow{2}{*}{ P value $=0.80$} \\
\hline
\end{tabular}

There were $10(16.7 \%)$ cases in Child class A, $30(50 \%)$ cases in class B and 20(33.3\%) in class C. Thus, maximum patients were belonging to class B.

In patients belonging to Child class A,9 (90\%) cases had CAD. Amongst patients belonging to Child class B,27 (90\%) had CAD and patients of Child class C,19 (95\%) had CAD. There was not much difference between increasing frequency of CAD and increasing Child-Pugh class of liver cirrhosis and on applying test for association, there was no statistically significant difference between increasing Child -Pugh class of liver cirrhosis and CAD.

Table 7: Association of severity of cardiovascular autonomic dysfunction(CAD) and Child -Pugh class of liver cirrhosis

\begin{tabular}{|c|c|c|c|c|}
\hline \multirow{2}{*}{$\begin{array}{l}\text { Severity of } \\
\text { CAD }\end{array}$} & \multicolumn{3}{|c|}{ Child -Pugh class } & \multirow[b]{2}{*}{$P$ value } \\
\hline & $\begin{array}{l}\mathrm{A} \\
\mathrm{n}=10\end{array}$ & $\begin{array}{l}\mathrm{B} \\
\mathrm{n}=30\end{array}$ & $\begin{array}{l}\mathrm{C} \\
\mathrm{n}=20\end{array}$ & \\
\hline $\begin{array}{l}\text { Normal } \\
n=5\end{array}$ & 3 out of 5 & 2 out of 5 & $\begin{array}{l}0 \text { out of } \\
5\end{array}$ & \multirow{4}{*}{$\begin{array}{l}\mathrm{P} \\
\text { value }=0.007\end{array}$} \\
\hline $\begin{array}{l}\text { Early } \\
n=31\end{array}$ & 6 out of 31 & $\begin{array}{l}11 \text { out of } \\
31\end{array}$ & $\begin{array}{l}14 \text { out } \\
\text { of } 31\end{array}$ & \\
\hline $\begin{array}{l}\text { Definite } \\
\mathrm{n}=21\end{array}$ & 1 out 21 & $\begin{array}{ll}16 & \text { out of } \\
21 & \end{array}$ & 4 out 21 & \\
\hline $\begin{array}{l}\text { Severe } \\
n=3\end{array}$ & 0 & 1 out of 3 & $\begin{array}{l}2 \text { out of } \\
3\end{array}$ & \\
\hline
\end{tabular}

The association of severity of cardiovascular autonomic dysfunction (CAD) and Child -Pugh class of liver cirrhosis was statistically significant. The increasing severity of cardiovascular autonomic dysfunction was associated with higher Childs class of liver cirrhosis. Thus, as the severity of Child-Pugh class of liver cirrhosis increased, the severity of cardiovascular autonomic dysfunction also increased. 


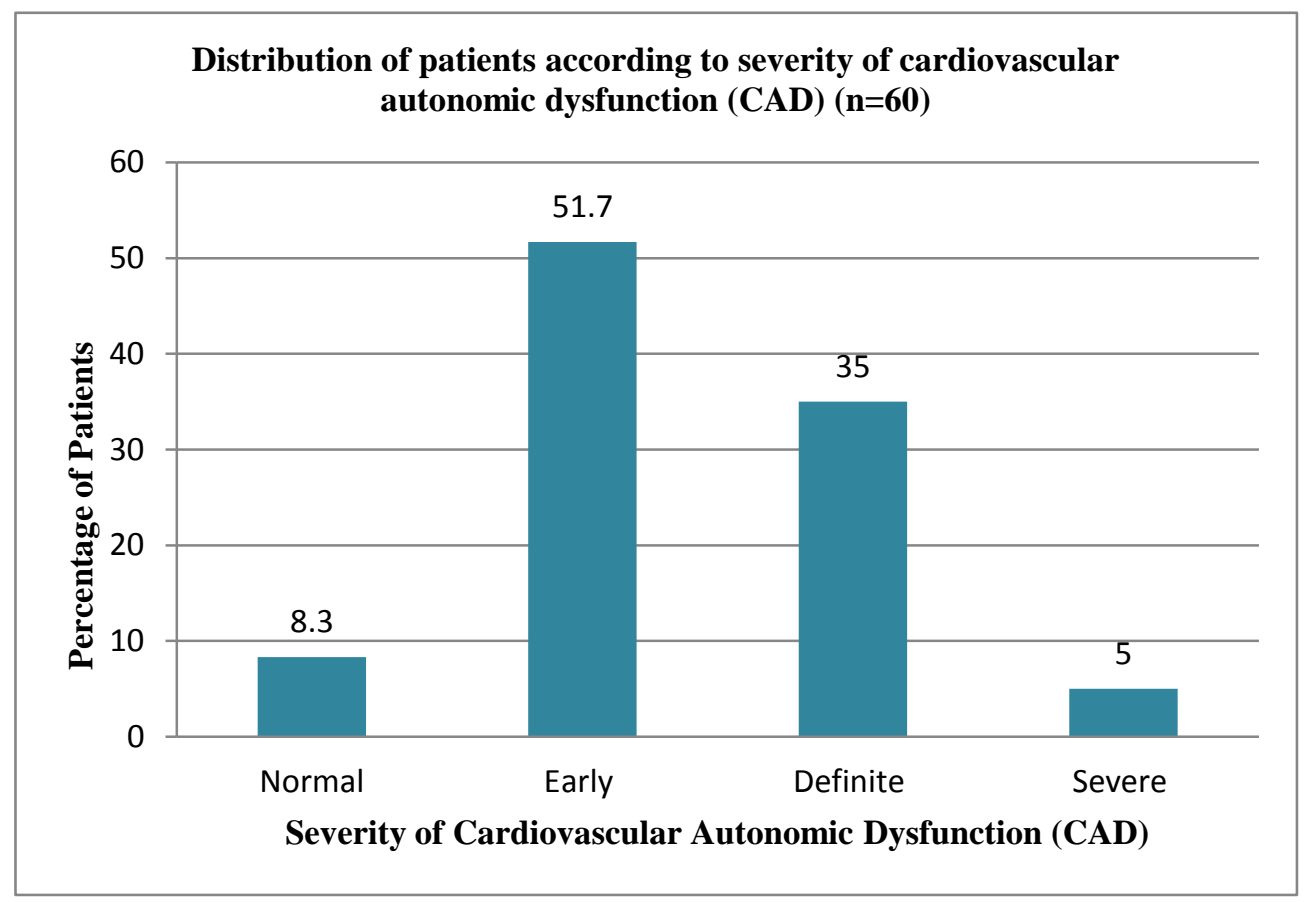

Graph 1 : Distribution of patients according to severity of Cardiovascular Autonomic Dysfunction (CAD) according to Ewing's criteria.

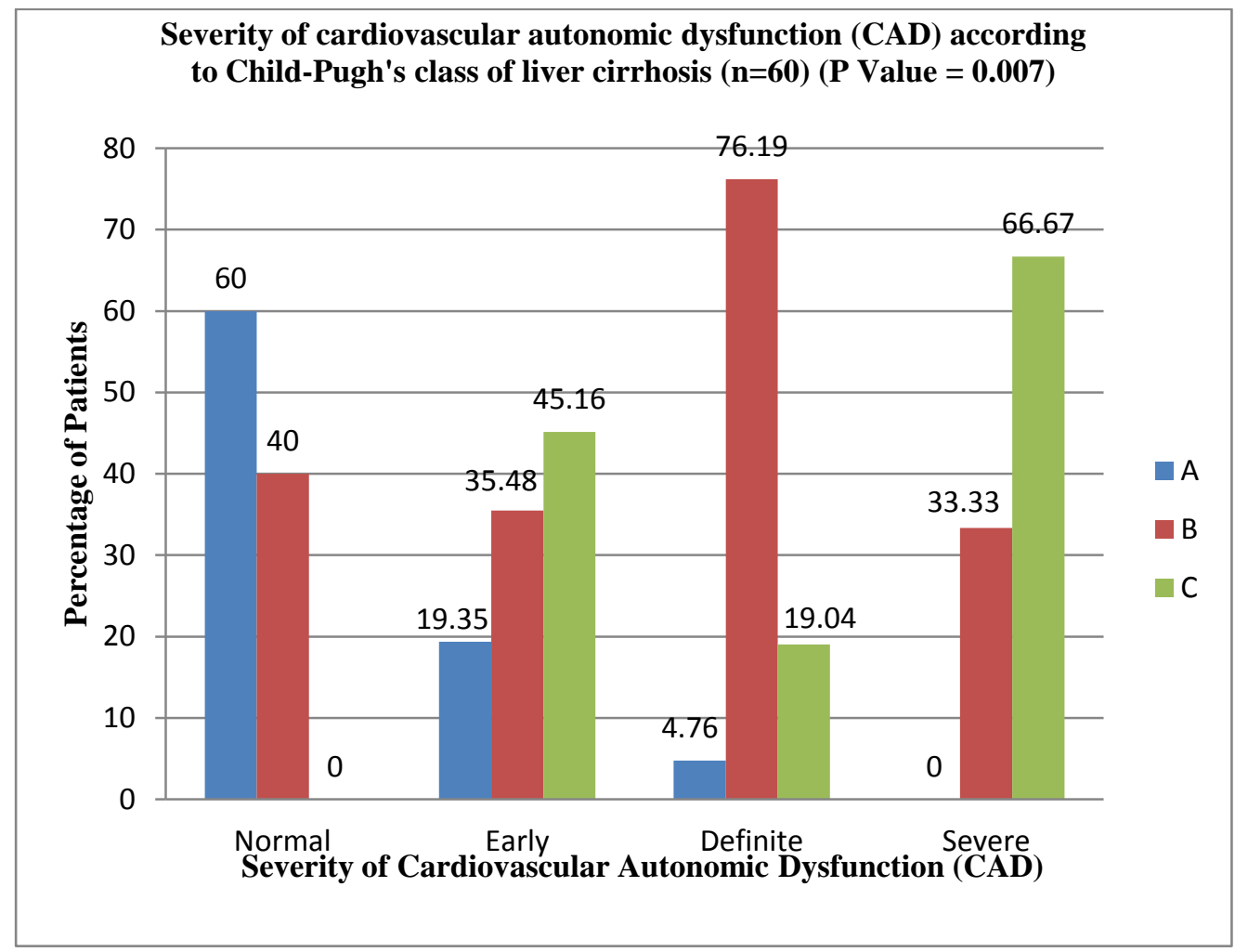

Graph 2 : Association of severity of Cardiovascular Autonomic Dysfunction (CAD) and Child-Pugh class of liver cirrhosis

(Class A, Class B and Class C) 


\section{Discussion}

Autonomic nervous dysfunction is a known complication of alcohol abuse. Autonomic damage is expected in some patients with alcoholic cirrhosis.

In this study, 55 out 60 (91.7\%) cases were found to have an abnormal result in one or more autonomic function tests. Only symathetic dysfunction was seen in $2(3.3 \%)$ cases, only parasympathetic damage in $44(73.3 \%)$ cases and $9(15 \%)$ out of 60 had combined sympathetic and parasympathetic dysfunction.

Similar results were observed in the study conducted by Bajaj and Agrawal where 16(80\%) out of 20 patients (10 alcoholics and 10 non alcoholics) of cirrhosis had autonomic dysfunction. None of the patient found to have sympathetic damage alone while only parasympathetic damage was observed in 8 cases, and combined i.e. parasympathetic and sympathetic damage was seen in 8 cases. ${ }^{11}$

Gentile et al found autonomic neuropathy in $60 \%$ (71\% in alcoholic group and $57 \%$ in the non alcoholic group) out of 113 cases of cirrhosis studied. $^{12}$

Kempler $\mathrm{P}$ et al in their evaluation of 121 patients with chronic alcoholism-33 without

liver disease, 33 with fatty liver, 33 with cirrhosis, 10 with biliary cirrhosis and 12 patients of cirrhosis of another origin. They found autonomic reflex damage in all cases and observed significantly more damage in those with liver disease. ${ }^{13}$ Hendrickse and Triger reported cardiovascular autonomic dysfunction with predominantly parasympathetic abnormality in $35 \%$ of the patients with chronic liver disease. ${ }^{14}$

In our study, heart rate response to standing was the most frequent (41 cases,68.3\%) abnormal autonomic function test in cases with alcoholic liver cirrhosis. $15(25 \%)$ cases had abnormal heart rate response to deep breathing,9(15\%) had abnormal blood pressure response to sustained handgrip and 17(28\%) had abnormal Valsalva ratio.
Bajaj and Agrawal in their study also noted heart rate response to standing as the most frequently (11 out of 20,55\%) abnormal test in cirrhotics. ${ }^{11}$

Barter and Tanner in their study noted there was a significant difference between alcoholics and controls for the mean heart rate response to standing(30:15 ratio; alcoholics 1.03, controls 1.13; p,0.001) with 10 alcoholics showing a definitely abnormal value $(<1.0)$ compared to 3 controls. Heart rate response to standing was the most sensitive test $(82 \%)$ with high specificity. Heart rate response to Valsalva manuoevre and postural drop in blood pressure were highly specific but of low sensitivity.8 patients had abnormal heart rate response to deep breathing, 8 patients had abnormal blood pressure response to sustained handgrip and 7 patients had abnormal Valsalva ratio. ${ }^{1}$

The association of cardiovascular autonomic dysfunction (CAD) and Child -Pugh class of liver cirrhosis was not found to be statistically significant in the present study.

In this study, according to Ewing,s criteria of severity of CAD,31(51.7\%) had early,21(35\%) cases had definite and $3(5 \%)$ cases had severe CAD. There were $30(50 \%)$ cases in Childs class B followed by $20(33.3 \%)$ cases in Childs class C and $10(16.7 \%)$ cases in Childs class A. The association of severity of cardiovascular autonomic dysfunction and Child Pugh class of liver cirrhosis was statistically significant. The increasing severity of cardiovascular autonomic dysfunction was associated with higher Childs class of liver cirrhosis.

Hendrickse and Triger reported a strong correlation between the abnormal autonomic function tests and Child Pugh score $(\mathrm{p}<0.0001)$.In their study, they found autonomic dysfunction in $69 \%$ of Child class B and C patients and $23 \%$ in class A patients $(\mathrm{p}<0.0001) .{ }^{14}$ On the contrary, Gonzalez-Reimer et al in their study of 33 alcoholics, 20 of them cirrhotics, found a weak correlation between liver function and autonomic neuropathy $^{15}$ 
In the study by Jain $\mathrm{J}$ et al, higher magnitude (75.9\%) of autonomic neuropathy was found among subjects with Child Class $\mathrm{C}$ in comparison to subjects with Child Class B and A. Also, magnitude of autonomic neuropathy was more among cirrhotics with more than one reason (alcohol and hepatitis B) than cryptogenic cirrhosis. $^{16}$

\section{Conclusions}

This study shows that high prevalence of autonomic dysfunction is found in patients of alcoholic liver cirrhosis. Increasing severity of autonomic dysfunction as per Ewing's criteria is also significantly associated with increase in extent of the liver damage. The non alcoholic cirrhotics were not included in the study.Furthur prospective studies involving a larger number of patients are needed to delineate the factors responsible for the derangement and the final treatment measures if possible.

\section{Acknowledgement}

We, the authors of this article are greatful to the invaluable guidance and the keen interest of our seniors. We are greatful to all patients and their relatives for their utmost co-operation.

\section{Sources of support-none}

\section{References}

1. Barter F,Tanner AR.Autonomic neuropathy in alcoholic population. Postgrad Med J 1987;63:1033-6.

2. Thuluvath PJ, Triger DR. Autonomic neuropathy and chronic liver disease.Q J Med 1989;72:737-747.

3. Hendrickse MT,Triger DR.Peripheral and cardiovascular autonomic impairment in chronic liver disease: Prevalence and relation to hepatic function. J.Hepatology 1992;16;177-183.

4. Fleckenstein JF.,Frank S,Thuluvath PJ. Presence of autonomic neuropathy is a poor prognostic indicator in patients with advanced liver disease.Hepatology 1996; 23:471-475.

5. Marchesini G,Bianchi G,Amodio P,Salemo F,Merli M,Panella C,Loguercio C,Apolone G,Nero M,Abbiati R.Factors associated with poor health related quality of life of patients with cirrhosis. Gastroenterology 2001;120(1):170-178.

6. Maheshwari A, Thomas A, Thuluvath PJ: Patients with autonomic neuropathy are more likely to develop hepatic encephalopathy. Dig Dis Sci 2004 Oct; 49(10): 1584-8.

7. Milinvac B,Milinic N.Autonomic dysfunction in alcoholic cirrhosis and its relation to sudden cardiac death risk predictors. Gen. Physiol. Biophys 2009;28:251-261.

8. Ewing DJ,Clarke BF.Diagnosis and management of diabetic autonomic neuropathy.BMJ 1982;285:916-919.

9. Pugh RN,Murray-Lyon IM,Dawson JL,Pietroni MC,William R.Transection of the oesophagus for bleeding oesophageal varices.Br J Surg.1973 Aug;60(8):646649.

10. Kasper D,Fauci A,Longo D.Harrisons principles of internal medicine. $19^{\text {th }}$ edition.McGraw Hill;2015.Volume II chapter 357p.1989-1995.

11. Bajaj BK,Agrawal M,Krishna BR. Autonomic neuropathy in patients with hepatic cirrhosis.Postgrad Med J.2003;79: 408-411.

12. Gentile S,Marmo R,Peduto A,Montello F,Coltorti M.Autonomic neuropathy in liver cirrhosis:relationship with alcoholic etiology and severity of disease.Ital $\mathbf{J}$ Gastroenterol 1994;89:1544-1547.

13. Kempler P,Varadi A,Szalay F,Oravecz L,Kadar E,Kiss E.Autonomic neuropathy in chronic liver disease.Gastroenterol $\mathrm{J}$. 1990;50:187-189.

14. Hendrickse MT,Triger DR.Autonomic dysfunction and hepatic function in chronic liver disease.Gut 1990;31:A1164. 
15. Gonzalez-Reimers E,Alonso-Socas $\mathrm{M}$, Santolaria-Fernandez J,Hernandez-Pena, A.Conde-Martel,F.Rodriguez Moreno. Autonomic and peripheral neuropathy in chronic alcoholic liver disease.Drug Alcohol Depend 1991;27;219-222.

16. Jain J,Banait S,Singh R,Udan V,Rao T.Magnitude and pattern of autonomic neuropathy in cirrhosis of liver:A cross sectional study from central rural India.J Mahatma Gandhi Inst Med Sci 2015;20:66-73. 